\title{
Nonproteic Contents Interfere with the Analysis of Added Tryptophan in Feeds - Test of a Correction Model
}

\author{
Johannes Fontaine*, Elke Berlemann and Wolfgang Polzer
}

Evonik Degussa GmbH, Feed Additives, Animal Nutrition Services, Bldg. 913-205, P.O. Box 1345, 63403 Hanau, Germany

\begin{abstract}
The nonproteic, free tryptophan contents in 23 important feed ingredients were analysed. Wheat, its bran and middlings, soybean meal, sunflower meal and other vegetable feed ingredients contain significant fractions of free tryptophan, up to $38 \%$ of total tryptophan. These natural contents considerably interfere with the accurate determination of supplemented L-tryptophan in mixed feeds. Two correction methods were successfully tested in four feeds, which were each supplemented at two levels. They allow a distinct improvement in the analysis of tryptophan addition.
\end{abstract}

Keywords: Free, nonproteic Tryptophan, amino acid analysis, supplementation, blank value, mixed feed, feed ingredients, raw materials, wheat, wheat bran.

\section{INTRODUCTION}

In recent years, the significance of the essential amino acid tryptophan for animal husbandry has been intensively researched. Eder et al. [1] determined, for example, the optimum requirement of piglets and tested with different Trpsupplemented base diets. Susenbeth [2] provides a literature survey for pig feed and attempts to derive therefrom an optimum ratio of Trp to lysine content of feed. Corzo et al. [3] studied the Trp requirement of male broilers in the final feeding phase. The Trp requirement determined in research is currently increasingly achieved by feed producers at a reasonable cost by addition of supplemental L-Trp, particularly in the case of feeds with low crude protein contents.

In Belgium, a market study was conducted on the amino acid composition of pig feeds. The results of our laboratory obtained for supplemented Trp were often higher than the quantities actually added. In fact, we even analyzed non protein-bound Trp in feeds to which L-Trp has not been added. The goal of this study is therefore to test whether natural free Trp contents in raw materials could be the cause of this observation. Further, methods of blank value correction were tested in order to provide a distinctly more accurate report of the Trp actually supplemented than is possible with the analyzed content of free Trp.

Because in case of L-Trp addition the unsupplemented mixed feed samples are rarely available for measuring the natural contents of free Trp, a correction formula had to be developed and tested to estimate and subtract this "blank value".

\section{MATERIALS AND METHODOLOGY}

\section{Samples}

Our laboratory is dedicated to analytical service for amino acid determination that serves feed manufacturers throughout the world, investigating ca. 12,000 feed samples

*Address correspondence to this author at the Evonik Degussa GmbH, Feed Additives, Animal Nutrition Services, Bldg. 913-205, P.O. Box 1345, 63403 Hanau, Germany; E-mail: johannes.fontaine@evonik.com per year by wet chemical methods on its contents. The received raw materials and mixed feeds are recorded in LIMS, classified by sample type according to client data and ground and homogenized with a Retsch ZM 200 ultracentrifugal mill using a $0.5 \mathrm{~mm}$ ring sieve. Subsequently, they are usually analyzed for their total amino acid content following oxidation and acid hydrolysis [4]. For the determination of the total tryptophan contents, however, alkaline hydrolysis in a steamed autoclave is carried out with air excluded, because this amino acid is degraded in acid hydrolysis and in a hot oxygen containing solution [5, 6]. For this project, 170 samples were randomly selected from 23 important feed raw materials and tested for their free Trp contents.

\section{Analysis of Free Tryptophan}

As standards, L-Trp of minimal 99\% purity (Merck 108374) and as an internal standard, pure $\alpha$-Methyl-trp (Bachem F-1810 or Sigma M-8377) was used. For the analysis of added or nonprotein-bound Trp, $2.0 \mathrm{~g}$ of sample is extracted under weakly acidic conditions $(0.1 \mathrm{~mol} / \mathrm{L} \mathrm{HCl})$ with the internal standard $\alpha$-Methyl-trp added, at room temperature, and subsequently, after adjustment of the $\mathrm{pH}$, specifically analyzed with reversed phase C18 HPLC using fluorescence detection (excitation: $280 \mathrm{~nm}$; emission: 355 $\mathrm{nm})$. Our method follows the official EU analysis method [4, 5]. A typical repeatability $\mathrm{CVr}$ of $1.6 \%$ was determined by triplicate determination on 9 different wheat bran samples, thus the analysis is very precise. All analyses were conducted in duplicate and the average was reported; the individual values were allowed to deviate relatively from each other by no more than $5 \%$.

\section{Formula to Estimate the Natural Free Tryptophan} Content in Mixed Feeds

On the assumption that the percentage composition of the mixed feed is known in terms of its chief constituents, a typical blank value can be determined using the mean free Trp contents of the used ingredients:

$$
\mathrm{BV}_{\mathrm{i}=1}=\sum\left(\text { Share }_{\mathrm{i}} \mathrm{x} \text { Mean }_{\mathrm{i}}\right) / 100
$$


Table 1. Results of the Determination of Nonproteic (Free) Tryptophan in 23 Feed Ingredients

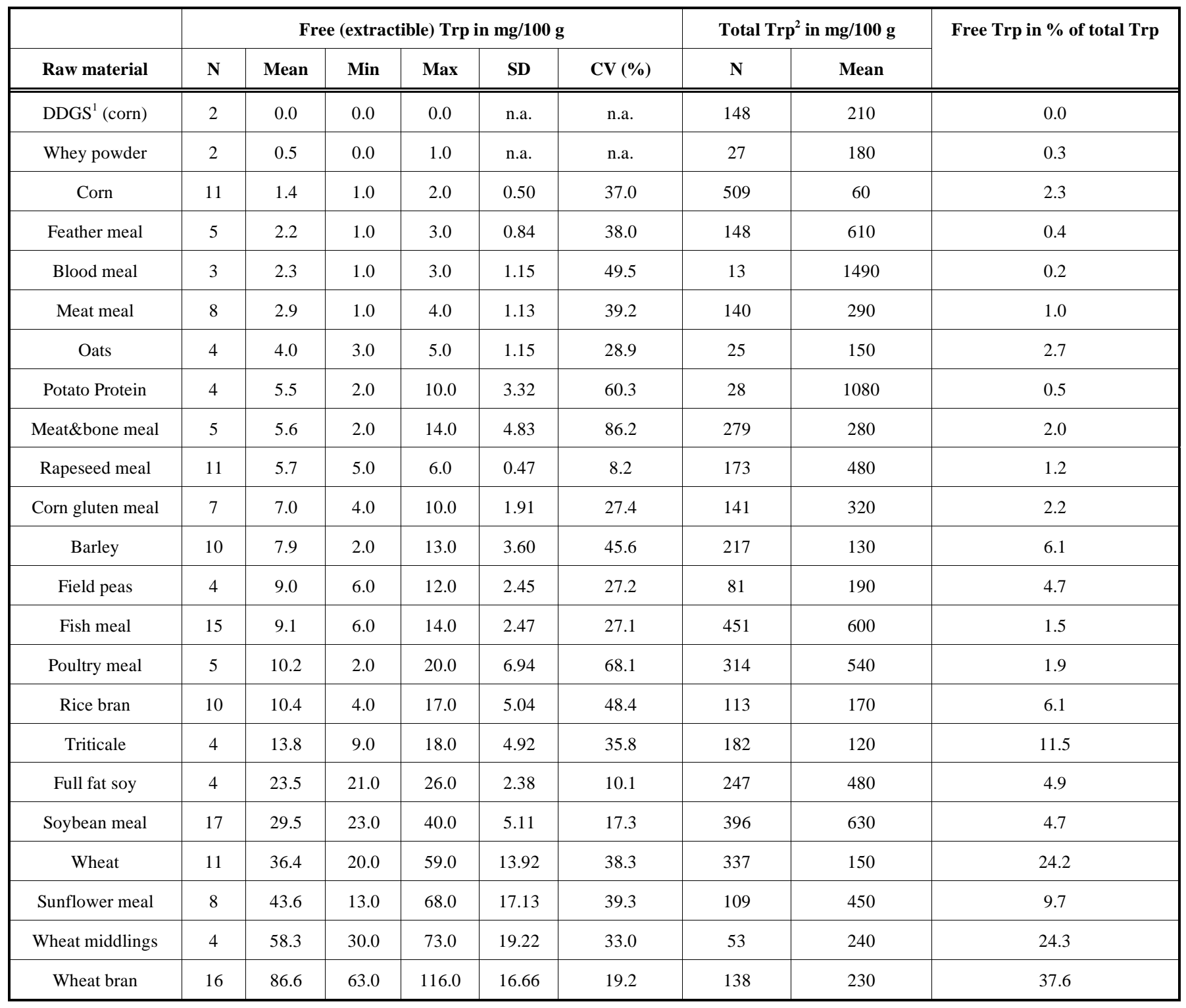

${ }^{1} \mathrm{DDGS}=$ distillers dried grains and solubles (from corn, residue of bioethanol production).

${ }^{2}$ Data are taken from Degussa AG, AminoDat [7].

$\mathrm{BV}_{\mathrm{Trp}} \quad=$ calculated Trp blank value in the feed in $\mathrm{mg} / 100 \mathrm{~g}$

$\mathrm{i}$ from 1 to $\mathrm{n}=$ code of the different raw materials in the feed

Share $_{\mathrm{i}}=$ share of raw material $\mathrm{i}$ in the mixture in $\%$

Mean $_{\mathrm{i}}=$ mean natural free Trp value $(\mathrm{mg} / 100 \mathrm{~g})$ of the raw material i (Table 1)

$\mathrm{BV}_{\text {Trp }}$ shall be subtracted from the analyzed free Trp content of the mixed feed to come closer to the actual supplementation rate.

\section{Production of Mixed Feeds for Testing the Correction Methods}

Four test feeds were made using commercial batches of corn, oats, barley, fish meal, wheat, soybean meal and wheat bran in different compositions and percentages, as shown in
Table 2. First, the individual raw materials were coarseground with a Retsch SR 2 rotor beater mill using a sieve with $3 \mathrm{~mm}$ spherical holes. Of each of the four basic feeds, $10 \mathrm{~kg}$ was weighed together from the various raw material batches and homogenized in a Lödige ploughshare mixer FM 50 (4 min mixing time at $130 \mathrm{rpm}$ ). For the supplementation $2 \mathrm{~kg}$ of the mixture in question was then combined in the small Lödige ploughshare mixer MR 5 with $400.3 \pm 0.5 \mathrm{mg}$ or $1000.1 \pm 0.5 \mathrm{mg}$ of L-Trp and thoroughly mixed for $4 \mathrm{~min}$ at $270 \mathrm{rpm} .200 \mathrm{~g}$ samples were then taken from the four unsupplemented feeds and the eight derived ones containing supplemented contents of $20.0 \mathrm{mg} / 100 \mathrm{~g}$ or $50.0 \mathrm{mg} / 100 \mathrm{~g}$ of L-Trp and analyzed for free Trp. Table 2 also shows the BV calculations of the free Trp contents based on the correction formula above. Further, also the unsupplemented base mixtures were investigated for free Trp, compared with the calculated contents and used for an alternative blank value correction. 
Table 2. Composition of the Trial Feeds to Test the Application of the Blind Value Correction Formula. Calculation of the Expected Blind Values

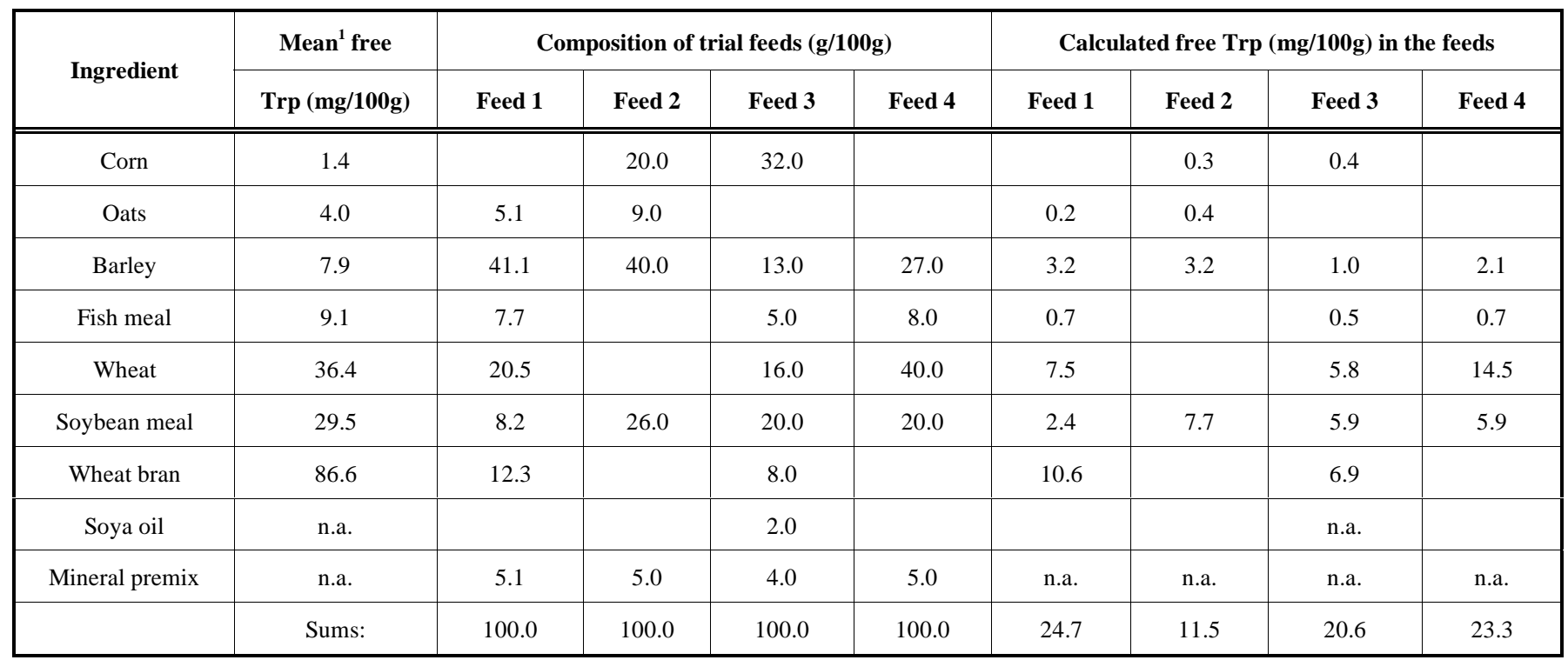

${ }^{1}$ See Table 1.

\section{RESULTS AND DISCUSSION}

\section{Nonproteic Tryptophan Contents in Feed Ingredients}

The results of our analyses are shown in Table $\mathbf{1}$. We see here a wide spectrum of free Trp contents, wherein DDGS, corn and whey powder contain almost none, important animal raw materials such as meat meal, blood meal and feather meal or oats contain very little free Trp, averaging less than $5 \mathrm{mg} / 100 \mathrm{~g}$. Another 9 raw materials contain an average of 6-10 mg/100 $\mathrm{g}$ of free Trp, including, in ascending order of content, potato protein, meat and bone meal, rapeseed meal, corn gluten meal, barley, field peas, fish meal, poultry meal by-product and rice bran. These are followed by triticale and then by the important feed ingredients full fat soy, soybean meal, wheat, sunflower meal, wheat middlings and wheat bran with considerable mean contents of free Trp ranging from 24 to $87 \mathrm{mg} / 100 \mathrm{~g}$ in this order. Very surprising are the high contents in wheat and its mill byproducts, in which the free Trp content averages $24 \%$ (wheat and middlings) to $38 \%$ (wheat bran) relative to the total Trp contents according to [7]. This evaluation (Table 1) also illustrates that only vegetable raw materials contain notable free Trp contents relative to the total content; these include field peas with just $5 \%$, barley and rice bran with about $6 \%$, sunflower meal with $10 \%$ and triticale with nearly $12 \%$. Recently, data on the contents of free Trp in vegetable products were published. Comai et al. [8] conducted free Trp analyses of individual samples of legume seeds and found $23 \mathrm{mg} / 100 \mathrm{~g}$ in beans, $6 \mathrm{mg} / 100 \mathrm{~g}$ in peas and $17 \mathrm{mg} / 100 \mathrm{~g}$ free Trp in full fat soy after duplicate extraction of the fat from the finely ground sample with acetone and subsequently, extraction of the free Trp in the residue with $37^{\circ} \mathrm{C}$ warm water. Thus, this method differs distinctly from our analysis and does not conform to the EU method, which prescribes extraction with dilute hydrochloric acid. These same authors [9] also investigated cereal flours with the same method. They found 7 $\mathrm{mg} / 100 \mathrm{~g}$ of free Trp in a corn sample, $3.6 \mathrm{mg} / 100 \mathrm{~g}$ in oats, $5.9 \mathrm{mg} / 100 \mathrm{~g}$ in barley, but only $3.5 \mathrm{mg} / 100 \mathrm{~g}$ in wheat.
Most analyses correspond quite well to our findings (range) in Table 1 with the exception of corn, which has a clearly higher value and of wheat, which represents a value only about one-tenth of our analyses. For validation of the EU method of Trp analysis in feeds [5, 6], a collaborative study with 12 laboratories was conducted and free Trp was determined in a wheat/soy mix. With good precision a result averaging $39.1 \mathrm{mg} / 100 \mathrm{~g}$ was measured and agrees well with our figures.

\section{RESULTS OF THE FOUR TEST FEED MIXTURES}

Table 3 shows the analysis data and describes the use of the blank value corrections. The mixed feeds actually contained free Trp in large amounts. The value calculated with the BV formula is identical to the analyzed value for Feed 2; it is 1.7 and $2.8 \mathrm{mg} / 100 \mathrm{~g}$ off for Feeds 1 and 3, respectively, while the difference of $5.3 \mathrm{mg} / 100 \mathrm{~g}$ is less favorable for Feed 4. As expected, for all four feeds, the analyses for supplemented Trp are higher than the added quantity; between 9 and $25 \mathrm{mg} / 100 \mathrm{~g}$ too high for the low supplementation of 20 $\mathrm{mg} / 100 \mathrm{~g}$ (47-125\% above addion); between 8 and 24 $\mathrm{mg} / 100 \mathrm{~g}$ too high at the higher addition rate of $50 \mathrm{mg} / 100 \mathrm{~g}$; thus, 16 to $48 \%$ above the target value.

Comparing the effect of the two blank value corrections, i.e., the BV calculated by means of the mean raw material contents of free Trp, and the real BV based on the analysis of the unsupplemented mixtures, then instead of the real analyses that average $16.7 \mathrm{mg} / 100 \mathrm{~g}$ too high, we found corrected contents averaging 3.3 and $1.7 \mathrm{mg} / 100 \mathrm{~g}$ below the target value, i.e., somewhat too low. Due to the variation in free Trp contents in feed raw material batches (min, max in Table 1), downward or upward deviations between the calculated $\mathrm{BV}$ and the analyzed BV, depending on the used batch, will always happen. The greater difference in calculated BV for Feed 4 is due to the fact that this feed consists of together $60 \%$ wheat and soybean meal and their batches used in this trial had free Trp contents below the average. The deviations from the target value, however, are always much smaller 
Table 3. Comparison of Two Different Methods for the Correction of the Trp Blind Values. Accurate Supplementation Rates can only be Determined Considering and Correcting for Natural Free Trp Contents in Feed Ingredients

\begin{tabular}{|c|c|c|c|c|c|c|c|c|c|}
\hline \multicolumn{4}{|c|}{ Blind values and supplementation rates } & \multicolumn{2}{|c|}{ Analysis of trial feeds } & \multicolumn{4}{|c|}{ Corrected Trp supplementation rates } \\
\hline \multirow[t]{2}{*}{ Code } & blind value1) & blind value & mented Trp & free Trp & added Trp & calculated BV & added Trp & analyzed BV & added Trp \\
\hline & $\operatorname{Trp}[\mathrm{mg} / \mathbf{1 0 0 g}]$ & $\operatorname{Trp}[\mathrm{mg} / \mathbf{1 0 0 g}]$ & {$[\mathrm{mg} / \mathbf{1 0 0 g}]$} & {$[\mathrm{mg} / \mathbf{1 0 0 g}]$} & {$[\mathrm{mg} / \mathbf{1 0 0 g}]$} & {$[\mathrm{mg} / \mathbf{1 0 0 g}]$} & {$[\mathrm{mg} / \mathbf{1 0 0 g}]$} & {$[\mathrm{mg} / \mathbf{1 0 0 g}]$} & {$[\mathrm{mg} / 100 \mathrm{~g}]$} \\
\hline Feed 1 & 24.7 & 26.4 & 0 & 26.4 & n.a. & 1.7 & n.a. & 0 & n.a. \\
\hline Feed 3 & 20.6 & 17.8 & 0 & 17.8 & n.a. & -2.8 & n.a. & 0 & n.a. \\
\hline Feed 4 & 23.3 & 18.0 & 0 & 18.0 & n.a. & -5.3 & n.a. & 0 & n.a. \\
\hline Feed 1 & 24.7 & 26.4 & 20.0 & 44.9 & 24.9 & 20.2 & 0.2 & 18.5 & -1.5 \\
\hline Feed 2 & 11.5 & 11.5 & 20.0 & 29.4 & 9.4 & 17.9 & -2.1 & 17.9 & -2.1 \\
\hline Feed 1 & 24.7 & 26.4 & 50.0 & 73.8 & 23.8 & 49.1 & -0.9 & 47.4 & -2.6 \\
\hline Feed 2 & 11.5 & 11.5 & 50.0 & 58.1 & 8.1 & 46.6 & -3.4 & 46.6 & -3.4 \\
\hline Feed 3 & 20.6 & 17.8 & 50.0 & 64.3 & 14.3 & 43.7 & -6.3 & 46.5 & -3.5 \\
\hline \multirow[t]{2}{*}{ Feed 4} & 23.3 & 18.0 & 50.0 & 67.9 & 17.9 & 44.6 & -5.4 & 49.9 & -0.1 \\
\hline & & & & Mean bias: & 16.7 & Mean bias: & -3.3 & Mean bias: & -1.7 \\
\hline
\end{tabular}

${ }^{1}$ Using the mean free Trp of the used feed ingredients (see Table 2).

than without BV correction (see Fig. 1). Using the calculated $\mathrm{BV}$, as should be expected, is somewhat less optimally than using the analyzed BV of the natural free Trp contents in the four mixed feeds.



Fig. (1). An accurate check of Trp supplementation at the usual low addition rates requires a correction for the naturally occuring free Trp contents (BV) in feed ingredients.

\section{CONCLUSION}

Our investigations clearly show that the natural free Trp contents in raw materials interfere with the accurate determination of supplemented Trp so substantially that no uncorrected analysis values should be reported. Ideally, unsupplemented feed could be available to analyze the real BV, as frequently possible in tests at universities. However, this is impossible in the case of commercial feeds from continuously operating feed mills. In this case, one can obtain the formulated composition of feed raw materials from the manufacturer and, on this basis, correct the analysis values using our BV formula. Due to the high native free Trp contents in wheat, soy and some other important vegetable raw materials combined with low supplementation rates (typically only 0.03 to $0.05 \%$ or 30 to $50 \mathrm{mg} / 100 \mathrm{~g}$ Trp in piglet feed), this is practically the only way to test the correct dosing of Trp into mixed feeds.

\section{ABBREVIATIONS}

$\mathrm{CVr}$, coefficient of variation $=$ relative standard deviation as within lab repeatability; rpm, revolutions per minute; Trp, tryptophan; BV, blank value = non proteic, free Trp, which was not added to the feed.

\section{REFERENCES}

[1] Eder K, Peganova S and Kluge H. Studies on the tryptophan requirement of piglets. Arch Anim Nutr 2001; 55: 281-297.

[2] Susenbeth A. Optimum tryptophan:lysine ratio in diets for growing pigs: Analysis of literature data. Livestock Sci 2006; 101: 32-45.

[3] Corzo A, Moran ET, Hoehler D and Lemme A: Dietery tryptophan need of broiler males from forty-two to fifty-six days of age. Poultry Sci 2005; 84: 226-231.

[4] COMMISSION DIRECTIVE 98/64/EC of 3 September 1998, establishing Community methods for the determination of aminoacids .... in feeding stuff and amending Directive 71/393/EEC, annex part A, Determination of Amino Acids. Official Journal of the European Communities, 1998; L257: 14-23.

[5] COMMISSION DIRECTIVE 2000/45/EC of 6 July 2000, establishing Community methods for the determination of vitamin A, vi- 
tamin E and tryptophan, annex part C, Determination of Tryptophan. Official Journal of the European Communities 2000; L174: 45-50.

[6] Fontaine J, Bech-Andersen S, Bütikofer U, de Froidmont-Görtz I. Determination of Tryptophan in Feed by HPLC - Development of an Optimal Hydrolysis and Extraction Procedure by the EU Commission DG XII in Three International Collaborative Studies. Agribiol Res 1998; 51: 97-108.

[7] Degussa AG. AminoDat ${ }^{\circledR} 3.0$ - The amino acid composition of feedstuffs,$- 6^{\text {th }}$ completely revised edition 2006; Degussa AG, Feed Additives Division, Hanau, Germany.
[8] Comai S, Bertazzo A, Bailoni L, Zancato M, Costa CVL and Allegri G. Protein and non-protein (free and protein-bound) tryptophan in legume seeds. Food Chem 2007; 103: 657-661.

[9] Comai S, Bertazzo A, Bailoni L, Zancato M, Costa CVL and Allegri G. The content of proteic and nonproteic (free and proteinbound) tryptophan in quinoa and cereal flours. Food Chem 2007; 100: 1350-1355. 